\title{
Barrierefreiheit
}

\section{Steht Ihre Praxis jedem offen?}

\author{
Behinderte Menschen sollen normal am gesellschaftlichen Leben teil- \\ nehmen können. Ausgerechnet im Gesundheitswesen herrschen aber \\ gravierende Defizite. Jetzt sind die Praxisinhaber gefragt.
}

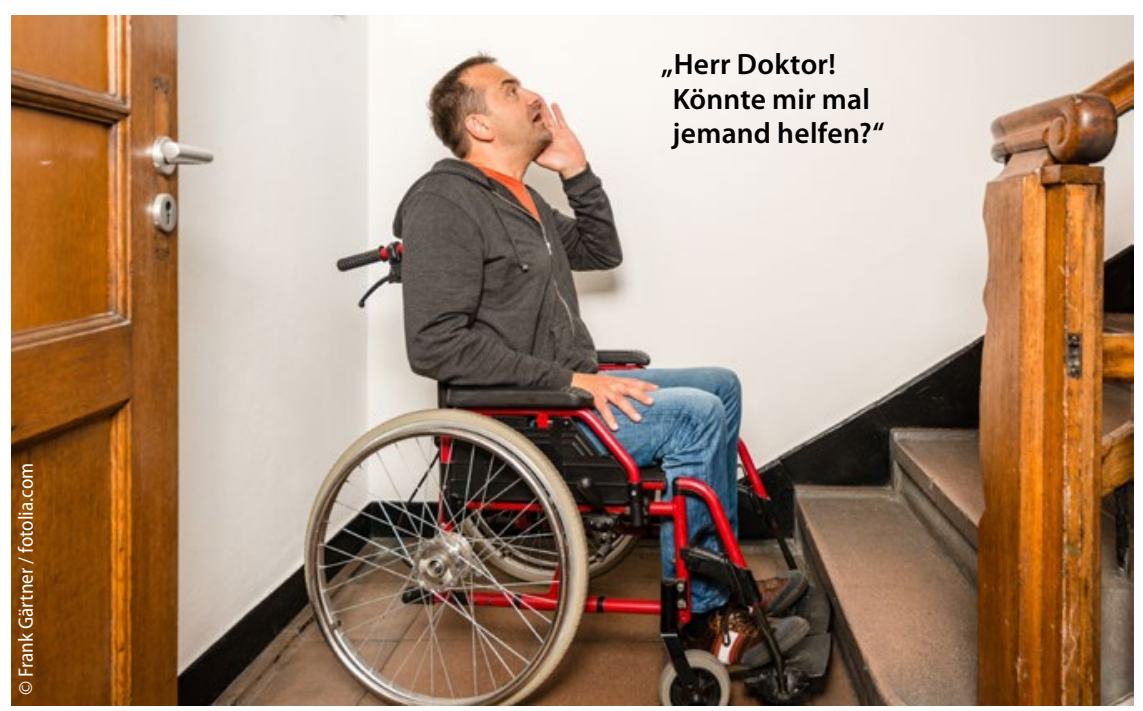

- In der Gesundheitsversorgung stoßen Menschen mit Behinderung oder Beeinträchtigungen nach wie vor auf viele Barrieren. Obwohl sich Deutschland mit der Unterzeichnung der UN-Behindertenrechtskonvention verpflichtet hat, private Güter und Dienstleistungen für behinderte Menschen zugänglich und nutzbar zu machen, liegt gerade im Gesundheitsbereich einiges im Argen.

Jeder Patient hat eigentlich das Recht auf freie Arztwahl. Diese Freiheit ist für viele zu Ende, wenn beim gewünschten Arzt ein ebenerdiger Zugang oder ein Aufzug fehlen. Auch barrierefreie Untersuchungsmöbel oder ein behindertengerechtes WC haben die wenigsten Praxen. Außerdem können sich Blinde und Sehbehinderte schlecht zurechtfinden, und Gehörlose sowie Hörgeschädigte haben Kommunikationsschwierigkeiten.

Dabei profitieren nicht nur Menschen mit Behinderung von barrierefreien
Arztpraxen, sondern auch ältere Patienten und all jene, die zeitweise in ihrer Mobilität eingeschränkt sind. Deshalb ist es aus Sicht des VdK völlig unverständlich, dass der Bereich der privaten Güter und Dienstleistungen im novellierten Behindertengleichstellungsgesetz völlig außen vor bleibt.

\section{Nur jede fünfte Praxis ebenerdig}

Aktuell ist lediglich jede fünfte Hausarztpraxis ebenerdig zugänglich, bei den Zahnärzten ist es sogar nur jede siebte. Die Berater unseres Verbands hören häufig von Praxen, wo Patienten auf Barrieren stoßen. Das schließt neben baulichen auch menschliche Barrieren ein. Sätze wie „Dann müssen Sie sich eine andere Praxis suchen“ sind keine Ausnahmen. Vor allem für Senioren oder Menschen mit Behinderung auf dem Land, wo die Facharztdichte gering ist, ist das eine Zumutung.

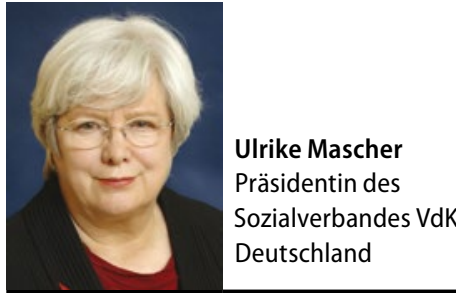

Dass es für die Praxen ein finanzieller Aufwand ist, barrierefrei zu werden, steht außer Frage. Daher ist es grundsätzlich begrüßenswert, dass die Bundesregierung mit dem „Nationalen Aktionsplan 2.0" Arztpraxen finanziell beim barrierefreien Umbau unterstützen will. Damit der politische Druck zunimmt, hat der VdK eine Kampagne ins Leben gerufen (siehe Kasten). Seit Januar haben bereits mehr als 35.000 Menschen die Forderung nach einem barrierefreien Deutschland unterstützt. Auf der Webseite sind bereits über 1.400 Barrieren gemeldet worden.

Beim Neubau von Praxen geht es überwiegend barrierefrei zu, weil bei der Zulassung durch die KVen Barrierefreiheit ein wichtiges Kriterium ist. Komplizierter ist die Lage bei den Bestandspraxen. Der VdK fordert, für den barrierefreien Umbau 80 Millionen Euro im Jahr bereitzustellen. Das sieht die KBV übrigens genauso. Sie setzt damit ein deutliches Zeichen: Kein Arzt kommt heute und in Zukunft mehr an den Bedürfnissen mobilitätseingeschränkter und älterer Patienten vorbei. Dafür sorgt schon der demografische Wandel.

- Die Autorin ist Präsidentin des Sozialverbands VdK.

\section{Menschenrecht Barrierefreiheit}

Der VdK ist mit über 1,7 Millionen Mitgliedern die größte Interessenvertretung behinderter und älterer Menschen in Deutschland. Mit der Kampagne www.weg-mit-den-barrieren.de engagiert er sich für Barrierefreiheit - ein Menschenrecht gemäß der UN-Behindertenrechtskonvention. 